on "Hay Fever," almost answers itself. The complaint, that I did not give credit to the gentleman who first used morphia combined with atropia, is not pertinent, inasmuch as the purpose of the paper was not to give a history of the various drugs recommended, but to give the Hay Fever Association the results of my study of the disease. "Subscriber" does not say that Dr. Morehead, of England, preceded me in the use of morphia and atropia, combined, as I recommended, for hay fever. I do not know that he did. I believed that I was the first to discover the efficacy of this prescription in hay fever, although I did not so state in the paper. I have used this prescription for several years successfully, not knowing that any one else had employed it except through my advice. Evidently the new members of the United States Hay Fever Association had not heard of Dr. Morehead's use of this prescription, for it is not mentioned in the Association's long list of remedies. However, if the remedy is efficacious it matters little who first happened upon the discovery; but if it be worthless, as "Subscriber" avers, I cannot understand why he (or she) is so concerned to have due credit given to the discoverer.

The fact that any given remedy may prove a failure in the hands of any one medical man, ought not to deter others from giving it a fair trial. I am always thankful for honest criticism from competent critics. Yours courteously,

SETh S. Bishop, M.D.

719 W. Adams St., Chicago, August 3, I887.

\section{CREMATION AND THE CATHOLIC CHURCH.}

Dear Sir:-The statement in THE Joynnal of Sept. I8, r886, relative to the position of the Catholic Church on the question of cremation having been discredited, I addressed a letter to Cardinal Gibbons on the subject. A copy of his reply is enclosed for your information and that of your readers. Yours; Respectfully, Charles A. Harvey.

Washington City, June 29, 1887.

\section{A. Harvey:}

Dear Sir:-Cardinal Gibbons bids me acknowledge the receipt of your letter of the $23 \mathrm{~d}$. He directs me to say that the Catholic Church discourages cremation as at variance with the practice of the people of God in the old dispensation and opposed to the cherished traditions of the Christian religion.

Respectfully, Yours in Christ,

JOHN T. WheLAN, Secretary.

Cardinal's Residence, 408 North Charles Street, Baltimore, June 24, I887.

\section{BOOK REVIEWS.}

Gout and its Relation to Diseases of the Liver and Kidneys. By Robson Roose, M.D., F.C.S., etc. Third Edition. 8vo, pp. xii-i64. London: H. K. Lewis, 1887 .

The seven chapters of this valuable little book are devoted to: General Considerations with regard to Gout; Sources and Places of Origin of Uric Acid in the System; Theories as to the Nature of Gout; Causes of Gout ; Irregular Manifestations of GoutVisceral and Cutaneous Affections; Hepatic and Renal Disorders connected with Gout; and the Treatment of Gout and of various Disorders connected with it. Of these chapters no one is more interesting or useful than that on the irregular manifestations of gout, to which too little study has been given. If anything, it could be wished that this chapter was longer.

This book is a comprehensive exposition of the subject, well written, and the reader is at all times convinced that it was written because the author had something to say. The chapter on treatment is of great value, and he must be unusually well informed who can learn nothing from it.

Outlines for the Management of Diet; or, The Regulation of Food to the Requirements of Health and the Treatment of Disease. By EDwarJ Tunis Bruen, Assistant Professor of Physical Diagnosis, University of Pennsylvania; one of the Physicians to the Philadelphia and University Hospitals, etc. 8vo, pp. 138. Philadelphia: J. B. Lippincott Company, I887. Chicago: W. T. Keener.

There are many books on diet for the sick in our literature, but very few which contain any good advice on "Regulation of Food to the Requirements of Health in Different Perinds of Life," which is the subject of Dr. Bruen's second chapter. And there is one paragraph in this chapter which should be framed and posted conspicuously in every house in the land: "No stimulating drinks of any kind should be used by the young or growing persons. Milk or water or dilute cocoa should be the only beverages. Coffee and tea may thus be reserved for later periods of life, when their stimulative properties may sup. port the nervous system; whereas, if the patient has been overstimulated while formative forces are at work, it is often impossible to prevent the development of an irritated and unbalanced state of the nervous system, which many persons notice in young children, without understanding the cause or how easily the trouble might be obviated."

That portion of the third chapter, "Special Plans for Diet," which deals with infants' foods is replete with information and good suggestions; but some space should have been devoted to the necessity of giving water to infants, especially in hot weather. Beef-tea and broths are discussed, but we find no mention of meat extracts and but little of meat juice.

As the title implies, we find in the book only outlines for the management of diet, and in so small a work one could not expect to find a complete treatise on diet and alimentary hygiene. It is the third of a series of "Practical Lessons in Nursing" now being issued by the publishers. The author has given us very satisfactory outlines for the management of diet, both in health and disease. 